\section{Elephant in the room}

We read with interest the article by Aggarwal et al on repository corticotropin injection $(\mathrm{RCI})$ in the treatment of refractory polymyositis and dermatomyositis (PM and DM) published in the Annals of the Rheumatic Diseases. ${ }^{1}$

The authors, who are well-respected researchers in the field of myositis, have done a good job in conducting a small openlabel trial of RCI in the treatment of PM/DM using validated disease activity measures and outcome measures. Whether these patients were truly 'resistant' is debatable, since only 3 of the 11 patients were treated with intravenous immunoglobulin (IVIG) before entering the study. Also, three serious adverse events related to the study drug among 10 patients in a 6-month period (all requiring hospitalisation, one being disseminated zoster with pneumonitis and not counting patients with incident hypertension and hyperglycaemia) should be a major cause of concern and would invalidate their assertive statement ' $\mathrm{RCI}$ was generally well tolerated with a reasonable safety profile'. They have mostly toned down the efficacy conclusions drawn from their case series, although 'promotional' language creeps in at some places, such as '....support the concept of RCI as a novel immunomodulatory therapy for myositis beyond the steroidogenesis effect.'

It is telling that we are still publishing and reading 'case reports' on the only Food and Drug Administration (FDA)-approved therapy for the treatment of PM and DM. It is also a sad reflection on an 'approved drug' that was never held to the same standards of showing efficacy and safety in prospective, double-blind, placebo-controlled trials that other drugs have to go through. The authors call it a 'proof-of-concept' study, which is an odd statement given RCI is FDA approved and marketed to treat $\mathrm{PM} / \mathrm{DM}$ and then state that this is 'the first clinical trial of RCI in adult DM \& PM using rigorous methodology', which nullifies previously published case studies, which form the so-called 'evidence' for the use of RCI for myositis.

Unfortunately, the authors do not mention the 'elephant in the room', which is the outrageous price of this treatment. At its current wholesale acquisition cost of $\$ 36382$ per 400 unit $5 \mathrm{~mL}$ vial, a 24 -week course of RCI therapy at 80 units twice a week as given in their study would require 10 vials and cost $\$ 363820$. Although the authors of this manuscript have nothing to do with the pricing decisions related to RCI, and they do suggest a cost-benefit analysis, we recommend readers to take into account the excessive costs of RCI before considering this treatment for their patients with inflammatory myositis.

Daniel M Hartung, ${ }^{1}$ Kirbee Johnston, ${ }^{1}$ David M Cohen, ${ }^{2}$ Thuan Nguyen, ${ }^{3}$ Atul A Deodhar, ${ }^{4}$ Dennis N Bourdette ${ }^{5,6}$

${ }^{1}$ College of Pharmacy, Oregon State University/Oregon Health \& Science University, Corvallis, Oregon, USA

${ }^{2}$ Department of Medicine, Division of Nephrology and Hypertension, Oregon Health \& Science University, Portland, Oregon, USA

${ }^{3}$ School of Public Health, Oregon Health \& Science University, Corvallis, Oregon, USA ${ }^{4}$ Division of Arthritis \& Rheumatic Diseases, Department of Medicine, Oregon Health \& Science University, Portland, Oregon, USA

${ }^{5}$ Department of Neurology, Oregon Health \& Science University, Portland, Oregon, USA

${ }^{6}$ MS Center of Excellence-West, VA Portland Health Care System, Portland, Oregon, USA

Correspondence to Dr Atul A Deodhar, Department of Medicine, Division of Arthritis \& Rheumatic Diseases, Oregon Health \& Science University, Portland, Oregon OR 97239-3098, USA; deodhara@ohsu.edu

Contributors All authors contributed to the content of the article, edited the content and gave permission to submit.

Funding This research received no specific grant from any funding agency in the public, commercial or not-for-profit sectors.

Competing interests None declared.

Provenance and peer review Not commissioned; internally peer reviewed.

(c) Article author(s) (or their employer(s) unless otherwise stated in the text of the article) 2019. All rights reserved. No commercial use is permitted unless otherwise expressly granted.

\section{Check for updates}

To cite Hartung DM, Johnston K, Cohen DM, et al. Ann Rheum Dis 2019;78:e11.

Received 12 January 2018

Accepted 15 January 2018

Published Online First 23 January 2018

\section{Linked}

http://dx.doi.org/10.1136/annrheumdis-2018-213020

Ann Rheum Dis 2019;78:e11. doi:10.1136/annrheumdis-2018-213008

\section{REFERENCE}

1 Aggarwal R, Marder G, Koontz DC, et al. Efficacy and safety of adrenocorticotropic hormone gel in refractory dermatomyositis and polymyositis. Ann Rheum Dis 2018;77:720-7. 